\title{
O Brasil e o Conselho de Segurança da Organização das Nações Unidas: dos anos 90 a 2002
}

\author{
Brazil and the UN: Struggle for a Role in the Security Council \\ (From the Nineties to the Present Day)
}

VIRGÍLIO CAIXETA ARRAES*

Rev. Bras. Polít. Int. 48 (2): 152-168 [2005]

\section{Introdução}

Na virada da década de 1980, a extinção da bipolaridade havia ocasionado a superação das duas vias de industrialização retardatária: o socialismo de Estado, sendo o centro o Leste europeu, e o nacional-desenvolvimentismo, cuja base houvera sido a América Latina. Nem um, nem outro haviam sido capazes de superar o sistema capitalista. Sendo ambas as possibilidades postas definitivamente de lado, os anos 90 assistiriam, em seu nascedouro, a prevalência incontestável do modelo formalmente democrático-liberal, sintetizado na expressão ufanista do fim da história - símbolo de um processo supostamente objetivo e insuperável da história. Se, por um lado, havia ruído o totalitarismo político, caracterizado notadamente pela vigência de apenas um partido político ou de uma burocracia altamente centralizada, fosse civil, fosse militar, emergia, por outro, o econômico, amparado pela estruturação de um mercado idealmente mundial: "O fim da Guerra Fria trouxe uma configuração inteiramente nova. Pela primeira vez na história, o capitalismo se proclama como tal, numa ideologia que anuncia a chegada de um ponto final no desenvolvimento social com a construção de uma ordem ideal baseada nos mercados livres, além da qual qualquer aperfeiçoamento substancial seria inimaginável. É esta a mensagem central do neoliberalismo (...)". ${ }^{1}$

\footnotetext{
* Investigador associado do Departamento de História da Universidade Nova de Lisboa e doutorando em História das Relações Internacionais pela Universidade de Brasília (arraesvc@uol.com.br).

${ }^{1}$ Kurz ainda ressalta que nem em uma nem em outra houve a questão de superação do capitalismo. Sobre o modelo de industrialização retardatária. KURZ, Robert. Com todo vapor ao colapso. Juiz de Fora: UFJF; Rio de Janeiro: Pazulin, 2004, p. 13, 173-4; "A Guerra Fria foi interna à hegemonia ocidental, e não externa, e o experimento soviético falhou pelo menos em parte porque imitou o desenvolvimento ocidental com excessiva fidelidade. Minha posição difere exatamente da descrição de Samuel Huntington de um choque de civilizaçôes, que especificamente exclui a União Soviética do Ocidente". BUCK-MORSS, Susan. A condição pós-soviética. Folha de São Paulo. São Paulo, Mais, p.10, 27 nov 2005; Acerca da citação. ANDERSON, Perry. Idéias e ação política na mudança histórica. Margem Esquerda: São Paulo, v.1, n.1, p. 87, 2003.
} 
Assim, em função da nova configuração político-econômica, aguardavase a reestruturação dos organismos internacionais, em especial da Organização das Nações Unidas, cujo Conselho de Segurança refletia bastante o arranjo original de poder datado ainda do período de sua fundação, em meados da década de 1940, onde havia vicejado o imperativo de estabelecer mecanismos com vistas a garantir a segurança de todos os países-membros, mas sob a supervisão institucional de cinco grandes potências, descrentes de acordos provindos de negociações ad hoc. Contudo, o controle das questôes podia ser aplicado individualmente por meio do exercício do poder de veto, efetivado por Estados Unidos e União Soviética sem restrições - pouco tempo depois de sua constituição, os membros permanentes do Conselho passariam a aceitar a abstenção como a ausência de veto. ${ }^{2}$

Em considerando o aspecto econômico como o mais relevante, dois candidatos naturais emergiriam: Japão e Alemanha, paradoxalmente os maiores derrotados da Segunda Guerra - ambos sem ser exportadores significativos de material bélico para países periféricos ou potências nucleares. Entrementes, o primeiro teria mais chances, porquanto a Alemanha, no âmbito da União Européia, acarretaria a terceira vaga, algo impensável para o restante do globo, cada vez menos eurocêntrico. Em se fiando na crença, mais tarde observada como ilusória, de que o sistema internacional caminhava para a ampliação da representatividade em seus principais organismos, países do Terceiro Mundo poderiam pleitear presença junto ao segmento mais importante das Nações Unidas. Desta forma, ao balancear-se um conjunto de predicados, Brasil, Índia, Egito, Nigéria, África do Sul, México, dentre outros, se habilitariam a um assento permanente no Conselho de Segurança, ainda que, em um primeiro momento, sem acesso ao poder de veto como os demais. Outrossim, não se poderia ignorar a aspiração por mais poder conciliar, ao admitir-se a hipótese de intervençôes coletivas autorizadas em face do desrespeito de direitos humanos ou decorrentes de motivações humanitárias. ${ }^{3}$

Hodiernamente, o Conselho de Segurança constitui-se de 15 Estados, em que cinco dispóem de assento fixo com o cobiçado poder de veto - Estados Unidos (EUA), Rússia, China, França e Grã-Bretanha - enquanto há dez outros com mandato de dois anos, distribuídos de acordo com critérios geopolíticos - cinco para África e Ásia; dois para América Latina e Caribe; e três para a

\footnotetext{
2 WIGHT, Martin. A politica do poder. Brasília: UNB, 198, p.176-8, LIANG, Yuen-Li. Abstention and Absence of a Permanent Member in Relation to the Voting Procedure in the Security Council. The American Journal of International Law. Washington, v.44, n.4, p.707-8, oct 1950.

3 "(Os membros do CS) aceitam plenamente a inclusão da Alemanha e Japão em igualdade de condições; e aceitam relutantemente, mas realisticamente, a inclusão de membros subdesenvolvidos”. GUIMARÂES, Samuel. Quinhentos anos de periferia. 2 ed. Porto Alegre: UFRGS; Rio de Janeiro: Contraponto, 2000, p.111; Sobre Japão e Alemanha. S.A. Let's Rethink the Security Council. Christian Science Monitor. Boston, p., 9 jul 1991; Acerca da ampliação do poder do CS. S.A. The UN on a Roll. Christian Science Monitor. Boston, p., 3 dec 1991.
} 
Europa: um para a parte leste e dois para a ocidental. Sua função primordial é a de manter a paz internacional. Para inúmeros países, mesmo em virtude do otimismo inicial do pós Guerra Fria, o corolário de uma imperturbabilidade sistêmica corporifica-se tão-somente diante de um conselho alargado pela razão seguinte: a quase quadruplicação dos filiados à ONU em suas seis décadas de existência com a presença de Estados a ombrear com quatro dos cinco fundadores, se comparados e conjugados os potenciais militar, econômico ou cultural. Atualmente, França, China e Rússia vislumbram seu funcionamento como forma de contrapor-se às aspiraçôes imperiais norte-americanas; por seu turno, EUA e Grã-Bretanha consideram-no propulsor para ações contra o terrorismo e Estados párias. ${ }^{4}$

A obtenção de uma vaga conciliar duradoura pode exprimir, de certa forma, o almejo da ampliação de prestígio, ou seja, o reconhecimento da sociedade internacional, com o objetivo de legitimar muitas vezes a execução de determinadas medidas políticas e econômicas como reformulação das forças armadas ou estabilização monetária, por exemplo. Durante a última década e meia, excluindo o sexagenário da instituição, houve dois momentos, embora sempre posteriormente malogrados, em que a possibilidade de alargamento do Conselho de Segurança havia sido mais viável: 1995, cinqüentenário da instituição, e 2001, ataque terrorista aos Estados Unidos. Saliente-se que, no entanto, alterações possíveis no funcionamento contemplam-se desde os anos 50 , já concentradas na perspectiva de ampliação dos membros vitalícios. ${ }^{5}$

\section{A obsessão da vaga permanente: da Liga das Nações à Organização das Nações Unidas}

Desde a existência de seu predecessor, o Conselho Executivo da Liga das Nações, a diplomacia brasileira exalta a meta de compor de forma fixa a instância decisória maior, de maneira que ampliasse seu prestígio regional. Assim, com o fim de satisfazer tal intento, corroborou-se a prática de que ser um membro temporário auxiliaria a pavimentação da obtenção do assento permanente afinal, pela primeira vez na história, Estados haviam voluntariamente prestado

\footnotetext{
${ }^{4}$ Sobre o posicionamento da França, Rússia e China. ALBRIGHT, Madeleine. United Nations. Foreign Policy. Washington, n. 138, p. 17, sep/oct 2003. Eventualmente, das duas vagas destinadas à Europa Ocidental, poder-se-ia valer a Oceania.

5 GOODRICH, Leland. The Un Security Council. International Organization. New York, v. 12, n. 3 , p. 286, 1958; De acordo com o embaixador junto à ONU, Celso Amorim: "Mas o importante para nós neste estágio é firmar o conceito de que deve haver ampliação do conselho, sobretudo expansão do número de membros permanentes, porque é aí que se encontra o maior desequilíbrio (...) Não podemos perder a oportunidade que este cinqüentenário nos oferece para reformar aspectos essenciais das Naçôes Unidas. A expansão do Conselho de Segurança é a principal reforma discutida. Não descartaria a possibilidade de esse assunto ser resolvido no prazo de um ano". ROCHA, Daniela. Brasil busca vaga na elite das Nações Unidas. Folha de São Paulo. São Paulo, p.1-24, 25 jun 1995.
} 
deferência política e jurídica a uma organização internacional talhada para ser duradoura e operacional. Depois de três assembléias gerais, onde havia composto a instância máxima da organização de modo temporário por causa da rotatividade, o Brasil passaria a cogitar o projeto de integrar-se a ela de modo perpétuo a partir de outubro de 1922. Em face da ausência dos Estados Unidos, o Brasil traçaria a proposta de ocupar temporariamente, ao menos, a vaga destinada àquele país. Não obstante a resistência britânica à solicitação, a diplomacia brasileira elevaria a sua representação à categoria de embaixada, sendo o primeiro Estado a fazê-lo, a fim de manter sua posição inicial. Em março de 1926, sem apoio britânico, francês e latino-americano, o Brasil observaria sua pretensão encerrada, de forma que, três meses mais tarde, renunciaria ao seu assento temporário, após sete anos ininterruptos, para posteriormente retirar-se da Liga das Naçôes. ${ }^{6}$

Nos debates da configuração da ONU durante agosto de 1944 em Dumbarton Oaks, de acordo com as memórias de Cordell Hull, titular do Departamento de Estado, os norte-americanos haviam sido favoráveis à participação do Brasil no Conselho de Segurança em pé de igualdade com os demais possíveis membros. A justificativa havia derivado do fato de que o país possuía território continental, população e potencial de desenvolvimento e, por conseguinte, as condições requeridas para instalar-se ao lado dos vencedores da Segunda Guerra Mundial. Contudo, a delegação britânica, encabeçada por Sir Alexander Cadogan, e a soviética, por Andrei Gromyko, recusariam a presença. Para ambos, afora os quatro grandes - Estados Unidos, União Soviética, Grã-Bretanha e China - seria considerada tão-somente a admissão da França. Em novembro daquele ano, ciente da oposição européia, o Brasil então advogaria o pleito de membro temporário como alternativa. Em janeiro de 1945, a diplomacia norte-americana havia exposto que os assentos permanentes permaneceriam com os Estados capacitados a exercer missóes de manutenção de paz em escala mundial. Além do mais, a oposição tenaz soviética ao pedido brasileiro houvera sido reforçado, em parte, pela ausência de relaçóes diplomáticas formais desde 1918. A Conferência de San Francisco, em abril de 1945, sepultaria definitivamente a aspiração nacional primeira, ao constatar a ausência de apoio dos países latino-americanos. No entanto, em janeiro de 1946, no correr da primeira Assembléia Geral, o Brasil seria o mais votado

\footnotetext{
6 VARGAS, Eugênio. A candidatura do Brasil a um assento permanente no Conselho da Liga das Nações. Revista Brasileira de Politica Internacional. Brasília, v.37, n.1, p. 7-9, 15-8, 1994; A Liga havia envelhecido precocemente. Muitos países reduziriam com pouco tempo sua estrutura administrativa junto à entidade por avaliar desfavoravelmente a relação entre presença diplomática e resultados obtidos. POTTER, Pitman. Permanent Delegations to the League of Nations. The American Political Science Review. Washington, v.25, n.1, p. 27-30, Feb 1931; Relativo à singularidade da organização. HARRIMAN, Edward. The League of Nations a Rudimentary Superstate. The American Political Science Review. Washington, v.21, n.1, p. 139, Feb 1927.
} 
para ocupar uma das vagas rotativas, graças certamente ao apoio estadunidense. Em dezembro de 1963, uma modesta reforma seria efetivada. ${ }^{7}$

\section{Em busca do assento sempre longínquo}

Diante da perspectiva de um ambiente em transição, o Brasil proporia em 1989, quando da abertura da $44^{a}$ Assembléia Geral das Naçóes Unidas, o alargamento da composição do Conselho de Segurança, com vistas a uma participação mais efetiva dos Estados periféricos. No início da década seguinte, o país, sob os auspícios do sepultamento da postura desenvolvimentista e da conseqüente aplicação do primado neoliberal, havia creditado em excesso o ajuste de suas necessidades internas à cadência externa da abertura e desregulamentação desmedidas, ao serem efetivadas de modo açodado. Deste modo, o percurso irregular da industrialização diversificada em nome da autosuficiência e projeção de poder praticado desde os anos 30 seria gradativamente substituído pela especialização no setor agrícola e extrativo em decorrência da visão de oportunidades restritas e, por derivação, da necessidade de alinhar-se com o centro de poder, a fim de encaixar-se na nova ordem internacional. Assim, esperava-se compensar a escassez de recursos tecnológicos e financeiros autóctones por meio do investimento externo direto (IED). Como destaca Boron: “(...) os regimes democráticos da América Latina adotaram, sob influência do neoliberalismo e dos economistas neoclássicos (...), o cálculo de custo/benefício como o critério fundamental na a elaboração de políticas públicas. A pergunta que os governos formulam não é a que deveriam: o que um Estado democrático deve fazer? Mas a que fazem é esta outra (...) 'quanto custa esta política e como repercutirá sobre o equilíbrio das contas fiscais’ (...) Este abandono dos critérios de justiça se revela claramente na 'mercantilização' dos processos políticos das democracias latino-americanas". ${ }^{8}$

\footnotetext{
${ }^{7}$ Sobre memórias de Hull, posicionamento das delegações da Grã-Bretanha e União Soviética, possibilidade de membro temporário do Conselho de Segurança, oposição soviética, ausência de consenso entre países latino-americanos e apoio final norte-americano. HILTON, Stanley. Brazilian Diplomacy and the Washington-Rio de Janeiro 'Axis' during the World War II Era. The Hispanic American Historical Review. Durham, v.59, n.2, p.223-28, 1979; Acerca de 1963. CARLSSON, Ingvar. The U. N. at 50: A time to reform. Foreign Policy. Washington, n.100, p.6, 1995; Relativo às memórias de Hull e predicados do Brasil. SILVA, Carlos Eduardo da. FHC dá a Clinton livro que pede Brasil em órgão da ONU. Folha de São Paulo. São Paulo, p.1-5, 23 out 1995; Meio século mais tarde, o presidente Fernando Henrique Cardoso sugeriria o assento permanente ao Brasil em reconhecimento à participação no conflito. ROSSI, Clóvis, SIMŌES, Rogério. Tucano quer reduzir inflação. Folha de São Paulo. São Paulo, p. 1-7, 6 maio 1995.

${ }^{8}$ BORON, Atílio. A coruja de Minerva. Mercado contra democracia no capitalismo contemporaneo. Petrópolis: Vozes, 2001, p.256; Sobre a industrialização brasileira. ONIS, Juan de. Brazil on the Tightrope Toward Democracy. Foreign Affairs. New York, v.68, n.4, p.137-8, 1989; O novo comportamento podia ser verificado nas negociaçōes do Acordo Geral de Tarifas e Comércio (AGTT/Gatt) entre 1990 e 91 na chamada Rodada Uruguai. CRUZ JR, Ademar, CAVALCANTE, Antônio Ricardo, PEDONE, Luiz. Brazil's Foreign Policy under Collor. Journal of Interamerican Studies and World Affairs. Coral Gables, v.35, n.1, p.124-5,39, 1993; SARDENBERG, Ronaldo. Diplomacia brasileira tem participação ativa na
} 
No novo ambiente, o país havia-se aproximado mais dos Estados Unidos, tendo por símbolo inicial a viagem de Fernando Collor, presidente eleito mas não empossado, em janeiro de 1990 àquele país. Assim, assinalavam-se ajustes na conduta da política externa, voltada para a diversificação geográfica nos anos anteriores. $\mathrm{Na}$ área militar, o Brasil anunciaria na Assembléia Geral da ONU, em setembro de 1990, o fim do projeto de eventuais explosões nucleares e, no final de novembro, desenvolveria uma postura diplomática comum com a Argentina diante da Agência Internacional de Energia Atômica (Aiea). Além do mais, ambos os mandatários apoiariam o comportamento norte-americano em face do Iraque e do AGTT - mesmo assim, a diplomacia brasileira queixarse-ia do protecionismo estadunidense. Em visita ao Brasil, o presidente George Bush havia salientado em discurso ao Congresso de 3 de dezembro de 1990 que: "The changes you are carrying out in your economy - reducing the size of the state, privatizing enterprises, combating inflation and liberalizing trade - are the keys to growth and prosperity in the global economy of the $21^{\text {st }}$ century, whose outlines we already see today"?

Após uma crise política cuja saída havia sido a destituição do presidente Collor, o Brasil voltaria, aos poucos, a executar sua rotina administrativa. Todavia, o projeto de alteração administrativa das Nações Unidas não havia sido esquecido. Aos olhos do mundo, em sendo falto de potência bélica, o governo brasileiro havia apresentado ao restante do mundo credenciais de democracia, pacifismo, juridismo e multilateralismo. Assim, o governo Itamar Franco aspirava ao ingresso permanente no Conselho de Segurança como representante regional ou periférico/em desenvolvimento. O propósito não havia sido solitário, ao mencionar países como Alemanha, Japão, Índia, Nigéria ou Egito, e contemplava a sua entrada, ainda que sem o direito de veto inicialmente. Apesar da manifestação do intento, o país não lograria consenso regionalmente, porquanto, na Cúpula do Rio de 1994, houve o posicionamento a favor do alargamento, porém sem indicação do representante. A Argentina, por exemplo, havia sido defensora da rotatividade de uma eventual vaga latino-americana.

ONU. Folha de São Paulo. São Paulo, p. 6 (Mais)-8, 18 dez 1994; O país figura no Conselho de Segurança nos seguintes períodos, sendo de todos os membros não permanentes o mais assíduo: 1946-7; 1951-2; 1954-5; 1963-4;1967-8; 1988-9; 1993-4; 1998-9; 2004-5. Destaque-se que até 199875 países dos 185 então filiados à ONU jamais haviam ocupado lugar no Conselho de Segurança. CROSETTE, Bárbara. Road to Seat At the U.N. Is Paved With Perks. New York Times. New York, p.1-4, 2 aug 1998.

9 Segundo Thomas Bierstecker, apud Belli, a liberalização econômica havia ocorrido em quase todo o mundo em desenvolvimento, de forma que houve 'o triunfo da política econômica neoclássica'. BELLI, Benoni. Revista Brasileira de Política Internacional. Brasília: IBRI, p. 10-1, v.48, n.1, 1996; BUSH, George. The US and Brazil: Fulfilling a Common Destiny. U.S. Department of State Dispatch. Washington, v.1, n.15, p. 314, 10 Dec 1990; Brazil, Argentina Eager for Details Of Bush's Plan. Christian Science Monitor. Boston, p. 4, 3 Dec 1990; S.A. President Collor's Visit to the United States. U.S. Department of State Dispatch. Washington, v.2, n. 25, p. 447, 24 Jun 1991; Sobre o protecionismo dos Estados Unidos. S.A. Brazil, Argentina Eager for Details Of Bush's Plan. Christian Science Monitor. Boston, p. 4, 3 Dec 1990; KRASNO, Jean. Brazil, Argentina Make It Official. Bulletin of the Atomic Scientists. Chicago, v.48, n.3, p. 10, Apr 1992; S.A. Bush Thanks Brazil Leader for Support in Gulf War. Boston Globe. Boston, p. 13, 19 Jun 1991. 
$\mathrm{Na}$ abertura da sessão da 49a Assembléia Geral, em setembro de 1994, o ministro das Relaçôes Exteriores (MRE), Celso Amorim, ratificaria a proposta inicial, não obstante reservas argentinas, ao enfatizar: "O fortalecimento do papel da Assembléia Geral e a ampliação do Conselho de Segurança, com a participação de países em desenvolvimento em todas as categorias de membros, são passos importantes e necessários no caminho da democratização e de uma maior legitimidade (...)

O Brasil tem participado ativamente do debate sobre a ampliação do Conselho de Segurança. Temos deixado clara nossa disposição de assumir todas as responsabilidades inerentes aos países que se credenciarem a ocupar assentos permanentes". ${ }^{10}$

$\mathrm{Na}$ mesma ocasião, Alemanha e Japão também haviam feito solicitação semelhante, o que ensejaria manifestação do Primeiro-ministro de Portugal, Durão Barroso, a favor dos três. $\mathrm{Na}$ opinião do ministro Amorim, a “(...) integração do Brasil como membro permanente pode acontecer dentro de um ou dois anos, se houver consenso dos países da comunidade internacional'. Para ele, Alemanha e Japão podiam entrar para o Conselho, dentro de um contexto que visasse países em desenvolvimento, cuja representação contava com a China apenas, se considerados critérios de "riqueza e bens de consumo". Todavia, o cariz antidemocrático do Conselho já houvera sido reconhecido pela diplomacia brasileira, de forma que se estava ciente das amplas dificuldades, apesar do otimismo. Naquele momento, passavam-se poucas semanas da instauração de um plano de estabilização monetária, de modo que se contraía a inflação, o que, por seu turno, havia possibilitado a melhora da imagem do país - "O Plano Real foi deflagrado numa conjuntura em que a fadiga da sociedade brasileira com os fracassos anteriores no combate à praga inflacionária já se transformava em desespero". ${ }^{11}$

\footnotetext{
${ }^{10}$ A transição não havia sido virtuosa, dadas as diferenças de visão de mundo entre os membros da composição presidencial como, por exemplo, no tocante ao modo de privatização. Debicada, parte da imprensa internacional havia comparado o Vice-presidente Itamar Franco ao seu correspondente norteamericano, Dan Quayle. No fundo, havia o propósito de continuidade do programa neoliberal, algo confirmado no discurso de posse de Franco. LAMB, Christina. An Awful Lot of Trouble in Brazil. The Spectator. London, v.269, n.8566, p.13, 12 sep 1992; S.A. Opening a Can of Worms in Brasília. The Economist. London, v.324, n.7772, p.36, 15 aug 1992; Editorial. Brazil Under Collor: Not All Bad. New York Times. New York, p.A24, 1 oct 1992; KAMM, Thomas. Brazil's Franco Vows to Pursue Market Reforms. Wall Street Journal. New York, p.A4, 31 dec 1992; “To preserve Collor's objectives, it would be better without Collor than with him" said Federal Deputy Jose Serra. KAMM, Thomas. Brazil Officials Act to Preserve Reforms amid Collor Scandal. Wall Street Journal. New York, p.A8, 27 aug 1992; Sobre a posição da Argentina e oposição à presença no Haiti. S.A. País pede mudanças em Conselho da ONU. Folha de São Paulo. São Paulo, p.1-4, 26 set 1994; Acerca do perfil do país. AMORIM, Celso. Folha de São Paulo. São Paulo, p.1-4, 27 set 1994.

11 Sobre o Plano Real e citação (p.118). BELUZZO, Luiz Gonzaga. Ensaios sobre o capitalismo no século XX. São Paulo: UNESP, UNICAMP, p. 117-20, 2004; "Está na natureza da política que nem todos os membros desempenhem o mesmo papel ou tenham o mesmo peso. O Conselho embute características antidemocráticas que vêm do imediato pós-Guerra e que se reforçaram notavelmente durante a época da Guerra Fria; nestes novos tempos que sugerem novas atitudes, longe está, porém, das intenções dos
} 


\section{A autoconfiança do Brasil no cinqüentenário da ONU}

Durante a proximidade de meio século de existência da ONU, estudos haviam sugerido a oportunidade de empreender um remodelamento, incluindo naturalmente o CS. Um deles, o da Comissão de Governança Global, aconselhava o alargamento por meio da criação de uma nova categoria, sem direito a veto, com mais cinco países permanentes: dois industrializados provavelmente, Japão e Alemanha - e um da Ásia, da América Latina e da África. Ademais, três outros se somariam às vagas alternadas, de forma que o total chegaria a 23. Naquela altura, os EUA haviam-se posicionado claramente a favor da incorporação do Japão e Alemanha, a despeito da oposição da Itália, e da elevação do número de componentes para 21. Em vez de nove, seriam necessários 14 votos para a obtenção do consenso. ${ }^{12}$

No primeiro semestre da gestão de Fernando Henrique Cardoso, a despeito de o ministro das Relaçôes Exteriores, Luiz Felipe Lampreia, ter afirmado que a área econômica seria a prioridade da ação multilateral, seu lugar-tenente, Sebastião do Rego Barros, afirmaria que “(...) não estamos em campanha pelo Conselho de Segurança, mas achamos que o Brasil tem que ser olhado, sob pena de o Conselho ficar desbalanceado". Em viagem aos Estados Unidos, o presidente solicitaria ao secretário-geral das Nações Unidas, Boutros Boutros Ghali, mais cinco vagas fixas, sendo uma delas endereçada ao país - Ghali não se manifestaria publicamente acerca do pleito. Entrementes, apesar de afirmar que o presidente Bill Clinton havia sido simpático à idéia de compartilhar mais responsabilidades na manutenção da paz mundial entre os países-membros da entidade, Cardoso advertiria: "Nesse processo, não se cabalam votos. Ou o país se credencia para o posto ou não. Nós achamos que o Brasil se credencia"

membros permanentes que mais se beneficiam dessa 'assimetria de poder' ceder qualquer de suas posições de força diplomática”. SARDENBERG, Ronaldo. O Brasil na Presidência do Conselho de Segurança das Nações Unidas. In: FONSECA JR, Gelson, CASTRO, Sérgio Henrique de. Temas de Politica Externa Brasileira II. 2. ed. Brasília: Funag; IPRI; São Paulo: Paz e Terra, 1997, 2v, v.1, p. 141; “(...) nearly two years into office, Mr Franco has begun to turn heads and hearts. Though it took some persuasion, and several palace revolts, last year he underwrote the tough stabilisation programme of his then finance minister, Fernando Henrique Cardoso, that brought in a new currency and - so far - has clipped inflation from nearly $50 \%$ a month in June to around 5\% in July". S.A. Brazil: More Truman than Quayle. The Economist. London, v.332, n.7877, p. 36, 20 Aug 1994; Sobre a citação de Amorim. ROCHA, Daniela. Amorim critica na ONU o isolamento imposto a Cuba. Folha de São Paulo. São Paulo, p.1-4, 27 set 1994; Acerca da postura portuguesa. S.A. Menem reivindica as ilhas Malvinas na ONU. Folha de São Paulo. São Paulo, p. 2-12, 28 set 1994; Relativo à Alemanha, Japão e china. ROCHA, Daniela. País quer ser mais ativo na economia global. Folha de São Paulo. São Paulo, p.1-10, 3 out 1994; Referente ao apoio. DURÃO BARROSO, José Manuel. Redescobrir Portugal. Folha de São Paulo. São Paulo, p. 1-3, 16 jul 1995.

12 Sobre o número 21. ALBRIGHT, op. cit., p. 21; Acerca da reforma proposta. CARLSSON, op. cit., p. 6-7; "The obsolete veto privilege and the ill use of the Security Council by the powerful are exalting a new colonialism within the very United Nations. Latin America and Africa do not have one single permanent member on the Security Council. In Asia, India has a population of almost one billion, but it does not enjoy that responsibility". S.A. THE U.N. AT 50; And Now for the Next 50 Years: New Promises, Familiar Demands. New York Times. New York, p. A8, 23 Oct 1995. 
- a tônica seria mantida em junho quando da efeméride do meio século de existência da entidade. ${ }^{13}$

Em julho de 1995, o adjunto do Departamento de Estado, Strobe Talbott, ponderaria em visita ao país que se o Brasil obtivesse o apoio da comunidade latino-americana, os Estados Unidos referendariam o pleito - para a diplomacia norte-americana, a prioridade seriam assentos para Japão e Alemanha. Todavia, a Argentina posicionava-se a favor da rotatividade no continente. A tônica seria mantida ao longo do ano, fosse por ocasião do pronunciamento de Cardoso sobre o cinqüentenário da instituição, fosse pelo discurso de Lampreia na abertura da 50a Sessão. Haveria referência constante entre legitimidade e representatividade - consoante o governo, na época, tanto Rússia bem como China seriam favoráveis ao Brasil no Conselho. ${ }^{14}$

No início de 1996, a postura seria de mais cautela: tanto em viagem à Índia, em janeiro, como em audiência com o secretário-geral Ghali, no mês seguinte, Cardoso havia ponderado que o Brasil havia almejado a democratização maior das Nações Unidas - "É claro que países fortes como o Brasil e a Índia querem ter uma participação mais ativa. Isso não quer dizer que essa participação tenha que ocorrer no CS”. No entanto, não negava que o país tivesse sido 'sempre' candidato. Para Ghali, a pretensão brasileira era justa, mas o país devia participar de mais operações de paz e desconsiderar a questão da correlação entre peso regional e representação conciliar. Neste entretempo, a Argentina também se movimentaria. Em março e maio, Lampreia reiteraria o comportamento prudente do presidente, ao destacar o valor da presença nos organismos internacionais econômicos. No decorrer daquele ano, ante a ausência imediata de reforma, Lampreia, na época da abertura da $51^{\text {a }}$ Sessão da Assembléia Geral, reconheceria a dificuldade: "O assunto Conselho de Segurança está mais parado do que o trânsito na $1^{\text {a }}$ Avenida. Além disso, a inclusão do Brasil não é prioridade para nós". Entretanto, anunciaria que o país suspenderia a exportação de minas terrestres e assinaria o Tratado de

\footnotetext{
${ }^{13}$ Sobre a prioridade para área econômica. PINTO, Paulo. ministro confirma troca de dólares no paralelo. Folha de São Paulo. São Paulo, p. 1-9, 27 mar 1995; Acerca de Barros. ROSSI, Clóvis. Viagens buscam tornar o país interlocutor mundial. Folha de São Paulo. São Paulo, p. 1-8, 14 abr 1995; Relativo a Ghali. SILVA, Carlos Eduardo da. Brasil quer ONU dedicada ao social. Folha de São Paulo. São Paulo, p. 1-6, 19 abr 1995; Referente a Clinton e declaração de Cardoso. SILVA, Carlos Eduardo da. Governo propôs reformas demais, afirma presidente. Folha de São Paulo. São Paulo, p. 1-7, 23 abr 1995; p. 7.

$14 \mathrm{O}$ autor opina que uma vaga permanente plena, ou seja, com direito ao veto, devia ser concedida à América Latina, de maneira que um triunvirato, Brasil, Argentina e México, a utilizaria. SEINTENFUS, Ricardo. A batalha para melhorar as condiçōes humanas foi também perdida pelas Naçóes Unidas. Folha de São Paulo. São Paulo, p. 1-3, 22 jun 1995; S.A. ONU deve combater a fome, diz presidente. Folha de São Paulo. São Paulo, p. 1-4, 27 jun 1995; ROSSI, Clóvis. EUA querem Brasil mais envolvido em missóes de paz. Folha de São Paulo. São Paulo, p.1-9, 12 jul 1995; FALCÃO, Daniela. Lampreia defende ampliação do Conselho de Segurança. Folha de São Paulo. São Paulo, p.1-5, 26 set 1995; Sobre o apoio russo. SILVA (1995 out), op. cit., p. 1-6; SALOMON, Marta. China apóia Brasil em conselho da ONU. Folha de São Paulo. São Paulo, p. 1-8, 14 dez 1995.
} 
Proibição de Testes Nucleares, ao lado de 65 outros países, de sorte que reiteraria a tradição pacifista e jurídica brasileira. ${ }^{15}$

Em março de 1997, a 51 a Assembléia Geral da ONU apresentaria projeto de alteração do CS com o seguinte delineamento: mais cinco membros permanentes, sem direito a veto, e mais quatro rotativos - a França havia manifestado pouco antes sua concordância com a mudança, em que se incluíam Alemanha, Japão e mais três países do Sul. $\mathrm{Na}$ busca da consecução de seu projeto, o país assinaria a sua adesão ao Tratado de Não Proliferação de Armas Nucleares, a despeito de não ter obtido concessão alguma. Em julho, os Estados Unidos, por meio de Bill Richardson, embaixador perante a ONU, se posicionariam pela ampliação com um representante continental da África, América e Ásia, desde que mantidas as prerrogativas dos cinco fixos. Paralelamente, a Argentina, em se tornando "major non-NATO ally", ao lado da Coréia do Sul, Egito, Israel, Japão e Jordânia, buscaria a vaga conciliar, após modernizar-se - de modo muito modesto - militarmente. Ela só encerraria seu pedido se o Brasil aceitasse a rotatividade. A divergência platino-brasileira encontraria ecos no encontro do Grupo do Rio, com 14 países, que não definiria candidato a priori, embora insistisse nos três vês: vez, voto e veto. Para o ministro Lampreia, tanto a alternância bem como a ausência de veto não satisfariam o país - mais ponderado na questão, ele lembraria o aumento da anualidade e o envio de mais tropas em missões de paz, mas confirmaria a posição na abertura da 52a Assembléia Geral em setembro. De todo modo, poucos dias antes, em sua visão: "(...) Seria algo que reforçaria nossa interlocução com o mundo inteiro. O Brasil é visto como importante ator nas articulações na ONU; como país capaz de ser fator de equilíbrio e ponte entre países desenvolvidos e em desenvolvimento; país de diplomacia segura, tradição pacífica, ações refletidas e coerentes, que não cede a impulsos nem recorre a gestos histriônicos. Por isso, encontra-se entre os países mais procurados para consultas; sua liderança discreta e equilibrada é bem recebida dentro e fora da nossa região. (...) Não abriremos mão do que é natural, objetiva e universalmente reconhecido: que, se uma vaga permanente tiver de ser preenchida por um país latino-americano,

${ }^{15}$ De acordo com FHC, 'Isso não é uma reivindicação brasileira. O que o Brasil quer, como outros países, é que a ONU tenha uma legitimidade maior, que seja um fórum mais democrático'. FREIRE, Vinicius. ONU é tema de comentário. Folha de São Paulo. São Paulo, p.1-4, 24 jan 1996; FALCÃO, Daniela. ONU cobrará a dívida do Brasil. Folha de São Paulo. São Paulo, p.1-18, 25 fev 1996; MOSRRI, Sônia, MARIM, Denise. Países disputam uma cadeira no Conselho de Segurança da ONU. Folha de São Paulo. São Paulo, p. 1-6, 26 fev 1996; PINHEIRO, Daniela. Secretário é pessimista sobre Brasil na ONU. Folha de São Paulo. São Paulo, p.1-6, 1० mar 1996; "Lampreia diz que hoje é mais importante para o Brasil a participação em organismos que tratam de questōes econômicas, como o BIRD (Banco Mundial) e FMI (Fundo Monetário Internacional).

'Tornar-se um membro permanente do Conselho de Segurança seria uma espécie de ISO 9000 para o país. Beneficiaria também as empresas brasileiras. Mas o mais importante hoje são os fóruns econômicos mundiais'”. PINTO, Paulo. Para Itamaraty, FMI é mais importante. Folha de São Paulo. São Paulo, p. 1-10, 7 mar 1996; S.A. FHC defende mudanças em conselho das Nações Unidas. Folha de São Paulo. São Paulo, p. 1-8, $1^{\circ}$ maio 1996; DECIA, Patrícia. Brasil ataca falta de credibilidade da ONU. Folha de São Paulo. São Paulo, p. 1-13, 24 set 1996. 
o Brasil conta com credenciais que o habilitam legitimamente a apresentar-se ou ser apresentado para essa função (...) Falamos de um interesse permanente do Brasil (...) Não devem, portanto, ser fruto de um cálculo alheio à política externa. Em suma, o Conselho de Segurança é um tema importante para a diplomacia brasileira". ${ }^{16}$

Em visita ao Brasil, em outubro de 1997, o presidente Bill Clinton mencionaria uma vaga para a América Latina. Mesmo sem definir favoritos, a proposta dos Estados Unidos provocaria dissenso. $\mathrm{Na}$ mesma linha, o ministro das Relações Exteriores da Rússia, Ievguêni Primakov, afirmaria, em novembro, o apoio ao assento para o continente, não para o Brasil: "A Rússia concorda com Argentina e Brasil de que existe a necessidade de a América Latina estar representada no Conselho de Segurança. Mas quem ocupará esse posto deve ser resolvido entre os países latino-americanos". Ainda no mesmo mês, não obstante o presidente Jacques Chirac ter-se referido ao seu correspondente brasileiro como representante do México, o país, de acordo com o embaixador Sérgio Amaral, havia-se posicionado a favor do Brasil no Conselho de Segurança. ${ }^{17}$

No primeiro semestre de 1998, a tradição de pacifismo do Brasil sobrepujaria a questão conciliar; em fevereiro, houve especulação se o país apoiaria os Estados Unidos em face de novo confronto com o Iraque em troca da solidariedade da ampliação do Conselho, algo refutado pelo Itamaraty -

16 ISMAIL, Razali. Ambassador Razali suggests 24-member Security Council. United Nations Chronicle. v.34, n.1, p.30-1, 1997; "The two countries were also at loggerheads recently after President Carlos of Argentina said he would veto the award of a permanent seat on to the Brazil”. DYER, Geoff, WARN, Ken. Argentina and Brazil face fresh dispute. Financial Times. London, p.3, 12 sep 1997; BERNARDES, Betina. Chirac tenta conter influência dos EUA. Folha de São Paulo. São Paulo, p.1-8, 11 mar 1997; GAZIR, Augusto. Brasil vai renunciar a armas nucleares. Folha de São Paulo. São Paulo, p.1-7, 21 jun 1997; Editorial. Uma nova velha ONU. Folha de São Paulo. São Paulo, p.1-2, 21 jul 1997; GODINHO, Fernando. País quer comprar mais armas. Folha de São Paulo. São Paulo, p.1-15, 14 ago 1997; GODINHO, Fernando. Menem recua sobre veto ao Brasil na ONU. Folha de São Paulo. São Paulo, p.1-6, 20 ago 1997; GODINHO, Fernando. Grupo do Rio não chega a acordo sobre vaga na ONU. Folha de São Paulo. São Paulo, p.1-4, 22 ago 1997; Nesse sentido, Cardoso anunciaria a reformulação militar: a transformação do Estado Maior das Forças Armadas no Ministério da Defesa, a fim de unificar o interlocutor nas questões militares e de segurança na área internacional. Quase dois anos mais tarde, os três ministérios militares tornar-se-iam comandos subordinados ao Ministério da Defesa. NOGUEIRA, Rui. Defesa não extinguirá ministérios militares. Folha de São Paulo. São Paulo, p. 1-10, 27 ago 1997; LAMPREIA, Luiz Felipe. A reforma do Conselho de Segurança. Folha de São Paulo. São Paulo, p.1-2, 31 ago 1997; ASSUMPÇÃO, João. Brasil assume sua candidatura na ONU. Folha de São Paulo. São Paulo, p. 1-12, 23 set 1997.

17 "The U.S. expansion proposal has managed to offend much of the membership. Italy, the fifth-largest donor to the U.N., is furious at being left out, as is the Middle East. In the three regions that would supposedly benefit, the fraternal squabbling has already started. Would the Asia seat go to Indonesia or India or Pakistan? Would Mexico or Brazil or Argentina represent Latin America? Who would speak for Africa? While starting this bickering, the U.S. wasn't clever enough to propose throwing France off the Security Council for refusing to take responsibility for such world problems as Iran”. Editorial. UNreform. Wall Street Journal. New York, p.1, 21 Oct 1997; "Os EUA acham que o Conselho de Segurança tem de ser ampliado, que um assento permanente deve ser dado à América Latina (...) Eu acho que essa é uma área que não cabe a nós dizer aos latinoamericanos como fazer ou o que fazer, mas eu espero que venhamos a ter sim esse assento permanente no Conselho de Segurança para a América Latina”. CLINTON, Bill. Entrevista. Folha de São Paulo. São Paulo, p. 1-14, 15 out 1997; S.A. ministro russo diz que não apoiou Brasil. Folha de São Paulo. São Paulo, p. 1-11, 26 nov 1997; S.A. Para Planalto, Chirac teve pequeno lapso. Folha de São Paulo. São Paulo, p. 1-8, 27 nov 1997. 
em havendo o conflito, teria de haver uma resolução do CS. Em maio, o governo brasileiro denunciaria o Acordo de Cooperação de Uso Pacífico da Energia Nuclear, assinado em janeiro de 1996, por causa de testes nucleares realizados pela Índia, apesar do apoio hipotecado dias antes em uma possível reforma. De acordo com o ministro interino, Sebastião do Rego Barros: "Devemos reconhecer que a explosão não facilita a discussão sobre a expansão do CS, que já teve pouco progresso nos últimos dez anos"; por fim, haveria a confirmação da prioridade do relacionamento com a Argentina em detrimento da cadeira, caso esta não aceitasse o pleito brasileiro. Em junho, Brasil, Argentina e África do Sul seriam convidados pelo G-8 para debater o tema da energia nuclear, exatamente pela renúncia em fazer uso militar dela. de. Na ocasião, Lampreia sobressairia o impacto de posturas distintas na disputa da reforma do Conselho, de sorte que: “(...) afeta inevitavelmente a candidatura da Índia. A Secretária de Estado (Albright) já fez declaraçóes públicas nas quais não deixa a menor dúvida (...) Mas é possível que o processo todo, em função desse problema na Ásia, sofra algum atraso (...) Esse convite (do G-8) e essa participação são uma demonstração do respeito que o Brasil e a Argentina obtiveram junto à comunidade internacional pela sua decisão e pelo fato de potencialmente poderem dar uma contribuição significativa nessa crise muito grave que ameaça seriamente a paz e a segurança internacional". ${ }^{18}$

No segundo semestre, talvez por influência do processo eleitoral presidencial, onde a economia seria forte alvo de debate, a retórica reformadora seria transmudada. Em vez do Conselho de Segurança, o G-8, agremiação dos países mais ricos do mundo, apesar da presença recente da Rússia; em vez de estabilidade política, haveria a econômica. Como sinal de ânimo, o ministro Lampreia diria que o país estava na 'antessala' do grupo, por ter sido convidado para duas reuniões, sendo uma delas a crise asiática. $\mathrm{Na}$ prática, a medida refletiria maior diversificação da atividade diplomática. Todavia, em setembro, quando da tradicional abertura da Assembléia Geral das Nações Unidas, Lampreia trataria do tema da reforma conciliar, mas sem descurar, entre outros, da necessidade de disciplinar mais a parte internacional financeira. ${ }^{19}$

\footnotetext{
18 CANTANHEDE, Eliane. Lampreia nega troca de favores com EUA. Folha de São Paulo. São Paulo, p.114, 6 fev 1998; MARIN, Denise. Itamaraty baixa tom de apoio a ataque. Folha de São Paulo. São Paulo, p.1-9, 7 fev 1998; GIRALDI, Renata. Índia quer Brasil em conselho de Segurança. Folha de São Paulo. São Paulo, p.1-12, 7 maio 1998; ROSSI, Clóvis, NATALI, João Batista. Brasil rompe acordo de energia com a Índia. Folha de São Paulo. São Paulo, p.1-15, 19 maio 1998; NATALI, João Batista. FHC admite desistir de cadeira na ONU. Folha de São Paulo. São Paulo, p.1-10, 23 maio 1998; VERSIANI, Isabel. Corrida armamentista favorece Brasil na ONU, diz Lampreia. Folha de São Paulo. São Paulo, p.1-8, 13 jun 1998. ${ }^{19}$ Saliente-se que nem o fato de o presidente Cardoso ser convidado para integrar a $3^{\text {a }}$ Via, liderada por Bill Clinton e Tony Blair, traria benefícios concretos para o Brasil. SUZMAN, Mark. Clinton, Blair plan 'third way' summit. Financial Times. London, p. 3, 27 Aug 1998; Sobre o discurso de Lampreia. LITTLEJOHNS, Michael, SILVER, Laura. Clinton issues call to give priority to terrorism UN General Assembly. Financial Times. London, p. 4, 22 Sep 1998; ROSSI, Clóvis. Brasil troca o conselho da ONU pelo G-8. Folha de São Paulo. São Paulo, p. 2-3, 29 jul 1998; S.A. Brasil abre assembléia da ONU falando sobre a crise. Folha de São Paulo. São Paulo, p. 1-6, 18 set 1998.
} 
Intempéries econômicas internas: contenção temporária da aspiração

Entre o fim de 1998 e o início de 1999, o processo repentino de enfraquecimento da moeda brasileira influenciaria a política externa - de acordo com Lampreia, o elemento de descontinuidade adviria do impacto da instabilidade financeira global 'e, em especial, a desvalorização do real'. Posturas contra os fluxos de capital descontrolados integrar-se-iam mais e mais à agenda externa. Durante o encontro de cúpula entre América Latina, Caribe e União Européia, o presidente Cardoso, no entanto, voltaria a insistir no tema da reforma, a fim de reforçar a paz mundial, abalada com os ataques da Otan à Iugoslávia. Meses mais tarde, na abertura da sessão da ONU, o Brasil censuraria a demora da ONU para responder a questóes emergentes como a de Timor Leste ou Angola, o que o que causaria impaciência e frustração. Novamente, o presidente da Argentina, Carlos Menem, proporia a criação de uma vaga rotativa para a América Latina, ao afirmar que a “(...) categoria de membro permanente não deve ser introduzida nas regiões em que não existem”. O ministro Lampreia não havia mencionado a questão. Conciliador, Rego Barros, titular da Embaixada junto à Argentina, amenizaria: "O tema do assento permanente no Conselho de Segurança ocupa hoje baixíssima prioridade na agenda externa brasileira". Em novembro, perante a Cúpula de Florença, em que estavam cinco dos sete países mais ricos, Cardoso se posicionaria a favor de alteração dos organismos internacionais para alargar a legitimidade. ${ }^{20}$

Em face dos problemas econômicos internos, a prioridade conciliar seria realmente posta de lado. Diante das dificuldades, o ministro Lampreia havia comentado que o projeto 'Brasil potência mundial' estava arquivado, porquanto “(...) para tê-lo é preciso ter dimensão militar. Potência mundial significa capacidade de atuação militar em conflitos fora da fronteira. $\mathrm{O}$ Brasil, com os desafios sociais que tem, graves carências no povo, não pode gastar os recursos para criar uma potência militar". Editorial da Folha de São Paulo abordaria: "O sonho acabou. O ministro Lampreia descartou a idéia de transformar o Brasil em uma potência mundial, com peso em decisões estratégicas globalmente. Trata-se de notável inflexão no discurso e nas ações ensaiadas nos últimos anos. Principalmente durante o primeiro governo de FHC, o Itamaraty alimentava o sonho de tornar-se o país membro permanente do CS (...) Mas o Chanceler, em sua última viagem aos EUA, não voltou a pleitear o posto. É saudável o choque de realidade, na verdade um apelo raro ao bom senso (...)

\footnotetext{
20 Sobre a intervenção anual brasileira. S.A. U.N. Oratory: Pleas for Help, Pride in Democracy. New York Times. New York, p. A12, 21 Sep 1999; CARDOSO, Fernando Henrique. Discurso. Folha de São Paulo. São Paulo, p.1-6, 29 jun 1999; SOLIANI, André. presidente argentino defende presença de seu país em cadeira rotativa no Conselho de Segurança da ONU. Folha de São Paulo. São Paulo, p. 2-6, 23 set 1999; SILVA, Carlos Eduardo da. FHC pede regras para controlar capitais. Folha de São Paulo. São Paulo, p. 1-10, 22 nov 1999.
} 
Não é pela via militar que o Brasil deveria buscar sua inserção global. A alternativa mais pertinente é aumentar sua participação comercial e política". ${ }^{21}$

Em agosto, o embaixador dos EUA junto à ONU, Richard Holbrooke, viria ao Brasil tratar de dois temas: a maior participação do Brasil nas missões de paz e a alteração do Conselho: para ele, se o Brasil participasse mais, poderia reforçar seu pleito no CS. Do Brasil, a resposta seria a falta de recursos financeiros e a visão de que a reforma do Conselho estaria realmente fora das preocupações principais das grandes potências. No mês seguinte, na Cúpula do Milênio, haveria discrição em relação ao tema, sendo referenciado o protecionismo dos países ricos, sem tratar do tradicional tópico reformador. Em outubro, na Alemanha, Cardoso ainda tentaria conjugar reforma financeira e conciliar; sem ela, havia-se configurado um déficit de governança mundial, mas as declaraçóes seriam minimizadas pelo titular do Itamaraty: "O processo de discussão (do Conselho) ainda não chegou à fase decisória, pelo que seria prematuro interpretar o discurso como uma reivindicação". ${ }^{22}$

Em 2001, o tema conciliar já não ocuparia tanto a atenção do governo até o atentado terrorista de setembro nos Estados Unidos, em que novamente o país vislumbraria a oportunidade de alteração administrativa, com vistas a preparar a comunidade internacional de modo mais adequado para um cenário de perspectivas sombrias. Em outubro, em viagem à Espanha com o fim de debater democracia, Cardoso citaria o fortalecimento das Nações Unidas e de seus organismos de deliberação, alusão a reformas burocráticas. Poucos dias depois, na França, ele seria mais explícito, ao referenciar-se diretamente ao Conselho de Segurança: "Assim se justifica o pleito pela democratização dos mecanismos decisórios de poder, o que inclui o Conselho de Segurança da Organização das Nações Unidas, que deve ser ampliado e reformado para melhor refletir a realidade em que hoje vivemos. As instituições da governança internacional foram concebidas para reger o mundo da Guerra Fria. É chegado o momento de atualizar essas instituições às circunstâncias do século 21 ". ${ }^{23}$

Às vésperas da abertura da Assembléia Geral, adiada por causa do atentado, o presidente Cardoso reunir-se-ia com o presidente George Bush e defenderia

21 SOLIANI, André. Lampreia rejeita sonho de potência mundial. Folha de São Paulo. São Paulo, p.1-8, 24 abr 2000; Citação maior. Editorial. Adeus ao Brasil potência. Folha de São Paulo. São Paulo, p.1-2, 26 abr 2000; "A qualquer momento, desde que uma autoridade estrangeira aterrissasse no Brasil, ou alguém daqui botasse os pés lá fora, um repórter queria saber da candidatura ao Conselho de Segurança. Aos forasteiros a pergunta era feita em tom de cobrança pelo apoio à 'candidatura' brasileira". NOGUEIRA, Rui. Extravagância abortada. Folha de São Paulo. São Paulo, p.1-2, 24 abr 2000.

22 S.A. Brasil deveria colaborar mais com a ONU, diz embaixador dos EUA. Folha de São Paulo. São Paulo, p.A12, 19 ago 2000; DÁVILA, Sérgio. Brasil reclama do protecionismo de ricos. Folha de São Paulo. São Paulo, p.B14, 13 set 2000; S.A. presidente cobra lugar em conselho da ONU. Folha de São Paulo. São Paulo, p.A6, 6 out 2000; 1-JB, 19 jun 2000, p.11; 19 ago, 2000, p.11; 7 set 2000, p.10; FSP, 19 ago 2000, p.12; 13 set 2000, Dinheiro, p.14; 6 out 2000, p.6.

23 ROSSI, Clóvis. Fala de FHC omite crítica a pacote antiterror dos EUA. Folha de São Paulo. São Paulo, p.A4, 27 out 2001; CARDOSO, Fernando Henrique. Discurso. Folha de São Paulo. São Paulo, p.A8, 31 out 2001 . 
no fortalecimento das Nações Unidas a entrada brasileira no Conselho de Segurança - "Disse a ele a importância, para nós brasileiros de que houvesse uma participação maior nossa, inclusive nos organismos formais, como no CS”. Todavia, ele não revelaria qual havia sido o posicionamento do mandatário norte-americano, mais preocupado provavelmente com o encaminhamento de questôes ligadas ao terrorismo. No plenário da ONU, a tônica do discurso de abertura da Assembléia Geral seria a mesma da empregada na Europa poucos dias antes: "A força da ONU passa por uma Assembléia Geral mais atuante, mais prestigiada, e por um Conselho de Segurança mais representativo, cuja composição não pode continuar a refletir o arranjo entre os vencedores de um conflito ocorrido há mais de 50 anos (...) Como todos aqueles que pregam a democratização das relações internacionais, o Brasil reclama a ampliação do CS e considera ato de bom senso a inclusão, na categoria de membros permanentes, daqueles países em desenvolvimento com credenciais para exercer as responsabilidades que a eles impõe o mundo de hoje. Como considera inerente à lógica das atuais transformações internacionais a expansão do G-7 ou G-8". ${ }^{24}$

Em janeiro de 2002, o Brasil obteria o apoio da Rússia, quando da visita de Cardoso: "Essa decisão é significativa, porque é o primeiro (sic) dos cinco que concorda com isso (...) é um sinal de que o governo russo tomou uma deliberação de levar ao pé da letra o que nós sempre dissemos e quisemos, uma parceria estratégica com o Brasil". No mês subseqüente, viria de um candidato significativo a solidariedade: a Alemanha, que, por sua vez, receberia reciprocidade. Ressaltese que, àquela altura, o óbice maior ao país não partiria da Argentina, desmobilizada após década intensa de práticas neoliberais, mas do México. Em julho, relatório do Programa das Nações Unidas para o Desenvolvimento (Pnud) classificaria inúmeras organizações internacionais, dentre as quais o Fundo Monetário Internacional, o Banco Mundial e a Organização Mundial do Comércio, desprovidas parcialmente de legitimidade e eficiência. Outrossim, o relatório incluiria o Conselho de Segurança como antidemocrático, por causa do instrumento do veto, ao estabelecer dois tipos de Estados, a despeito de seu uso declinar a partir da segunda metade da década de $90 .{ }^{25}$

\footnotetext{
${ }^{24}$ AITH, Márcio. FHC e Bush têm encontro superficial. Folha de São Paulo. São Paulo, p. A12, 9 nov 2001; DÁVILA, Sérgio. FHC propõe 'globalização solidária' ao falar na ONU. Folha de São Paulo. São Paulo, p. A5, 11 nov 2001 .

${ }^{25}$ A França havia supostamente granjeado apoio ao Brasil (nota 17). Na Rússia, insistiria: "Também em nome da legitimidade, o sistema da ONU carece de atualização. O CS deve ser ampliado e reformado para melhor refletir a realidade de nossos dias (...) O importante, de todo modo, é que compreendamos a crise internacional como oportunidade de repensar os padrōes de convivência entre os povos". SILVEIRA, Wilson. Putin quer país em conselho da ONU. Folha de São Paulo. São Paulo, p. A4, 14 jan 2002; SILVEIRA, Wilson. Schröder apóia entrada do Brasil no Conselho de Segurança da ONU. Folha de São Paulo. São Paulo, p.A4, 15 fev 2002; O relatório cita Japão, Alemanha e Índia como possíveis membros permanentes, conquanto muitos defendam a instituição de assentos permanentes regionais, em face da indefinição do candidato mais plausível - Brasil - Argentina; Índia - Paquistão. United Nations Development Programme (UNDP). Human Development Report 2002. Deepening democracy in a fragmented world. New York, Oxford, p. 126, 32-4, 2002.
} 
No resto do ano, em virtude das eleições presidenciais, ficaria para plano secundário a modificação dos organismos internacionais. Na tradicional abertura da Assembléia Geral das Naçôes Unidas, o ministro Celso Lafer abordaria o tema de uma possível reedição da I Guerra do Golfo, além do protecionismo comercial praticado por países do $1^{\circ}$ Mundo - "O protecionismo e toda a sorte de barreiras ao comércio, tarifárias ou não, continuam a sufocar a economia dos países em desenvolvimento". ${ }^{26}$

\section{A ausência de ruptura na conduta da política exterior}

Não obstante a oposição política inicial, contida no programa eleitoral, o presidente eleito Luís Inácio Lula da Silva manteria em viagem aos Estados Unidos o apoio à proposta de um assento permanente nas Naçóes Unidas, ao solicitar um representante sul-americano e outro africano. Durante a campanha presidencial, sua coligação partidária havia creditado a inúmeras organizações internacionais, como o Fundo Monetário Internacional ou Banco Mundial, o perfil de porta-voz e executor da 'globalização neoliberal'. Desta forma, a agremiação havia bradado pela reforma ampla das entidades não só econômicas, mas políticas também como as próprias Naçôes Unidas, em vez de querer compor uma hierarquia instituída ainda na década de 1940, o Conselho de Segurança. Ainda assim, o futuro ministro Celso Amorim reiteraria a posição do novel mandatário: "O presidente eleito reafirmou, em Washington, a necessidade de o Conselho de Segurança ser democratizado. O mais é a forma. Não é fácil, pode levar um ano, dois, três, mas não se pode absolutamente abandonar a meta. O convite do presidente Bush ao presidente eleito Lula já é uma demonstração clara da importância que o Brasil tem, para, entre outros aspectos, a estabilidade regional e até além dela. Não deixa de ser curioso que um presidente republicano retome tese de um presidente democrata [Franklin Roosevelt] de que o Brasil deveria ter lugar permanente no Conselho de Segurança”. 27

Por fim, em face dos inúmeros problemas sociais internos, que prejudicam de forma incisiva a projeção externa nacional, não seria cabível, ao longo dos últimos anos, requerer a ratificação de uma suposta liderança regional no âmbito mundial, ao efetivar-se um dia em uma cadeira permanente junto ao Conselho de Segurança. A América do Sul desde a Guerra das Malvinas há pouco mais

\footnotetext{
${ }^{26}$ DÁVILA, Sérgio. Brasil defende solução pela via diplomática. Folha de São Paulo. São Paulo, p. A7, 13 set 2002;

27 AITH, Márcio, ALENCAR, Kennedy. Bush pede o apoio de Lula para luta contra o Iraque. Folha de São Paulo. São Paulo, p. A6, 11 dez 2002; ROSSI, Clóvis. ALCA não barrará política interna, diz Amorim. Folha de São Paulo. São Paulo, p. A6, 18 dez 2002; S.A. Concep̧̧ão e diretrizes do Programa de Governo do PT para o Brasil 2002. São Paulo: PT, p. 14, 2002; S.A. Programa de governo. São Paulo: PT, p. 7, 2002 .
} 
de duas décadas não traz transtornos de grandeza conciliar, de sorte que a região não encabeça preocupação alguma ordenada e conjunta dos cinco grandes. É possível que a insistência brasileira mais recente advenha do fato de que os Estados Unidos e Grã-Bretanha tenham, de modo involuntário, valorizado o Conselho de Segurança, ao desejar legitimar sua aliança militar no longo prenúncio da invasão do Iraque em março de 2003. A dificuldade em ampliálo não decorreria apenas da insuficiência de meios brasileiros, mas, no todo, da contraposição nacional a todos os demais aspirantes: Alemanha - Itália; Índia - Paquistão; Japão - China etc. ${ }^{28}$

Recebido em $1^{\circ}$ de junho de 2005 Aprovado em 15 de novembro de 2005

\section{Resumo}

A obtenção de um assento permanente no Conselho de Segurança da Organização das Nações Unidas tem sido uma aspiração constante da política externa brasileira desde o fim da Guerra Fria. Todavia, a ênfase interna na consecução de tal intento depende do êxito da aplicação da política econômica conjugado com alterações externas, como o atentado terrorista de setembro de 2001.

\section{Abstract}

A permanent seat in the United Nations Security Council has been a constant aspiration of the Brazilian foreign policy since the end of the Cold War. However, the domestic emphasis in this endeavour depends on the success of the economic policy in association with international changes, provoked by events such as the September $11^{\text {th }}$.

Palavras-chave - política externa do Brasil; Nações Unidas; segurança internacional Key words - Brazilian foreign policy; United Nations; international security

28 Segundo Joseph Nye, '(...) é preciso reformar a Organização das Nações Unidas e o Conselho de Segurança. No entanto, não será fácil chegar aos nomes, pois, para cada candidato, há ao menos um detrator de sua candidatura’. MORAES, Márcio de. China veta Japão no Conselho de Segurança. Folha de São Paulo. São Paulo, p. A15, 15 abr 2005. 